\title{
Screening of Antifungal Substances from Bovistella Radicata (Mont.) Pat and Their Antifungal Effect
}

\author{
Yong Ye \\ Hefei University of Technology \\ Qinghua Zeng \\ Hefei University of Technology \\ Kun Liu \\ Hefei University of Technology \\ zeng qingmei ( $\nabla$ zengqingmei@hfut.edu.cn ) \\ Hefei University of Technology
}

\section{Research article}

Keywords: antifungal activity, extracellular metabolites, HPLC, FT-IR, GC-MS, decanol

Posted Date: June 10th, 2020

DOl: https://doi.org/10.21203/rs.3.rs-33942/v1

License: (9) This work is licensed under a Creative Commons Attribution 4.0 International License. Read Full License 


\section{Abstract}

Background To analyse the antifungal active compounds in B. radicata alcohol extract, the alcohol extract was purified by column chromatography (macroporous resinD-101) and the active compounds was named as SPAF-1(the spore powder active fraction).

Results Alcohol extracts and SPAF-1 were submitted to GC-MS analysis, there were two characteristic peaks(peak1 and peak2) in Gas chromatogram. By comparing in NIST, the compound were 2-propyl-1pentanol corresponding to peak1 and decanal, n-decanol and 2E-decanol corresponding to peak2. The main constituents were decanal(24.3\%) n-decanol(27.9\%), 2E-decenol (21.2\%) and 2-Propyl-1-pentanol (13.6\%). Their MIC values were $62.5 \mu \mathrm{g} / \mathrm{ml}, 31.2 \mu \mathrm{g} / \mathrm{ml}, 31.2 \mu \mathrm{g} / \mathrm{ml}$ and $250 \mu \mathrm{g} / \mathrm{ml}$ against $T$. rubrum respectively. Furthermore, transmission electron microscope (TEM) analysis showed altered surface morphology in the majority of T. rubrum cells after treatment with SPAF-1.

Conclusions In this paper, we successfully separate SPAF- 1 from alcohol extract of $B$. radicata. The antifungal effect of SPAF- 1 is similar to positive control, the main component were decanal, n-decanol, 2E-decenol and 2-Propyl-1-pentanol, the anti-tinea pedis effect of them was obvious.

\section{Background}

Tinea pedis is a chronic fungal infection of the feet ${ }^{[1]}$. Patients that have tinea pedis may be affected by several pathogens, including filamentous fungi named Trichophyton rubrum and Trichophyton mentagrophytes ${ }^{[2]}$, as well as a yeast named Candida albicans ${ }^{[3]}$. T. rubrum is the main pathogenic fungi for tinea pedis, having a prevalence as high as $80 \%$ among all tinea-pedis-associated pathogenic microbes $^{[4]}$. Traditionally, to treat tinea pedis, synthetic fungicides such as fluconazole, itraconazole, echinocandins ${ }^{[5]}$, and miconazole nitrate, either by oral medication or external use ${ }^{[6]}$, have been used to treat this disease. Vermes et al. (2000) found that flucytosine and AMB (amphotericin B) were moderately effective in fighting against invasive fungal infections ${ }^{[7-9]}$. Similar studies on Itraconazole have demonstrated that it is effective against fungal infections ${ }^{[10]}$. However, due to side effects or the continuous drug resistance, some oral medications are unsafe for patients [11], and these chemicals also cause potential deleterious effects on the environment due to their residues ${ }^{[12-13]}$, which has prompted researchers to develop newer and safer antifungal agents. Generally speaking, natural products extracted from plants represent a rich resource for screening bioactive compounds ${ }^{[14]}$.

Puffballs are widely distributed in many provinces of China, and are represented by more than 100 species $^{[15]}$. Calvatia gigantean(Batsch ex Pers.) Lloyd, Calvatia lilacina (Mont.et Berk.) Lloyd, Lasiosphaera fenzlii Reich, Lycoperdon pyriforme Schaeff.:pers, Bovistella radicata (Mont.) Pat, Handkea utriformis (HU), H. excipuliformis (HE), and Vascellum pratense (VP) are all common medicinal puffballs. Although no longer edible in their mature state (because of their powdery consistency), these puffballs have been shown to be a source of active compounds of various biological activities. Puffballs are believed to have several therapeutic properties when used medicinally: hemostasis ${ }^{[16]}$, cough relief ${ }^{[17]}$, 
suppression of cell division, and antitumor ${ }^{[18]}$ and antimicrobial ${ }^{[19]}$ properties. Petrović $\mathrm{P}$, et al(2016) reported noticeable antimicrobial activity diversity for the methanol extracts obtained from Handkea utriformis (HU), H. excipuliformis (HE), and Vascellum pratense (VP) ${ }^{[20]}$. The spore powder of HFTU-PB1 has been used traditionally as a folk remedy for tinea pedis. Picked specimen (named HFUT-PB1) was dried and deposited at the herbarium of the Department of Biology, Hefei University of Technology (HFUT), China.

The aim of the present study was to evaluate the antifungal activity of the spore powder active fraction (SPAF) extracted from Bovistella radicata (Mont.) Pat and its fractions against different species of tinea pedis pathogens, including T. rubrum and T. mentagrophytes. The differences of antifungal activities and GC fingerprints between spore and sporophore powder were determined. The antifungal activities were evaluated in terms of their minimum inhibitory concentration (MIC) values and zone of inhibition(ZOI) values $^{[21]}$, and the chemical constituents responsible for this activity were identified.

\section{Results}

\section{In Vitro Antifungal Activity Assay}

The puffballs (B. radicata, C. gigantean, C. lilacina, L. fenzlii Reich, and L. pyriforme) exhibited different antifungal activity against $T$. rubrum, $T$. mentagrophytes, E. floccosum, and $C$. albicans. The results were shown in Table 1. Alcohol extract of $B$. radicata spore powder showed good activity against the tested microorganisms (MIC was 62.5 and $125 \mu \mathrm{g} / \mathrm{ml}$ ), while alcohol extract of $B$. radicata sopophore powder and other puffballs (C. gigantean, C. lilacina, L. fenzlii Reich, and L. pyriforme) showed weak activity against the fungus (MIC was about 250 and $500 \mu \mathrm{g} / \mathrm{ml}$ ).

\section{Table 1 MIC volues of puffball spore or sporophore powder}

$\operatorname{MIC}(\mu \mathrm{g} / \mathrm{ml})$

Test items T.rubrum T.mentagrophytes E.floccosum C.albicans

\section{TUTUTUTU}

B. radicata 62.5250125250125250125250

C. Iilacina Lioyd 250500250500250500500500

L.fenzlii Reich $500 \otimes 500500500500 \rrbracket 500500 \otimes 500$

L.pyriforme $500 \rrbracket 500500 \rrbracket 500250500500500$

C.gigantean $250500500 \rrbracket 500500 \rrbracket 500125250$ 


\section{Note}

T spore powder groups treated with alcohol, U sporophore powder groups treated with alcohol, Terbinafine is positive control.

As shown in Table 1, antifungal effect of $B$. radicata sporophore powder and other puffball alcohol extract performed poor antifungal activity. The zone of inhibition (ZOI) was observed in PDA medium inoculated with $T$. rubrum, after co-cultivation with different alcohol extracts from B. radicata and L.fenzlii Reich, The results were showed in Fig. 1.

Figure1. zone of inhibition(ZOI) of spore and sporophore powder from B.radicata

From Fig. 1, the inhibitory effects on the growth of $T$. rubrum suggested that antifungal compound maybe was from $B$. radicata spore powder.

\section{SPAF-1 preparation from $B$. radicata alcohol extract by macroporous resin D-101}

We focused on $B$. radicata spore powder alcohol extract for further extraction and purification. This portion was separated by column chromatography using macroporous resin D-101 with $90 \%$ ethanol as eluent. The antifungal effectiveness of alcohol extract from $B$. radicata, eluent fractions with distilled water(EF) and $90 \%$ ethanol (SPAF-1) were assessed against T. rubrum (the main pathogenic fungi of tinea pedis). The antifungal assay confirmed that the alcohol extract and SPAF-1 exhibited high antifungal effectiveness, while EF exhibited weak antifungal activity (MIC $=250 \mathrm{mg} / \mathrm{I})$. MIC of alcohol extract was $62.5 \mathrm{mg} / \mathrm{l}$. While SPAF-1 ( $90 \%$ ethanol eluent fraction) exhibited the most complete activity with a $100 \%$ inhibition rate at a concentration of $31.2 \mathrm{mg} / \mathrm{l}$.

\section{HPLC analysis of alcohol extract and SPAF-1 from $B$. radicata}

As stated above, alcohol extract and SPAF-1 from B. radicata have obvious antifungal activity, while the eluent fractions(EF) has weak antifungal activity. It meaned that the active ingredient(SPAF-1) could be purified by macroporous resin D-101. Alcohol extract and SPAF-1 were analysed by HPLC. The characteristic peak1(2.42 min) and peak2(16.04 min) were shown in Fig. 2B (SPAF-1), the results also demonstrated macroporous resin D-101 was a good selectivity for purification of SPAF-1.

Figure 2. HPLC chromatograms of SPAF-1 and alcohol extract from B. radicata spore powder

\section{Chemical constituent analysis of SPAF-1 by GC-MS and HPLC}

The antifungal substances in $B$. radicata were also analyzed by GC-MS, among the GC-MS chromatograms of alcohol extract of spore powder, sporophore powder and SPAF-1. More than 50 
compounds were identified from spore and sporophore powder of $B$. radicata by GC-MS. Fitting analysis results of spore and sporophore GC chromatograms showed that spore chromatograms presented characteristic peak P1(8.791 $\mathrm{min}$ ) and P2(17.825 min) (Fig. 3), the characteristic peak time was consistent with SPAF-1.

Figure 3. Fitting gas chromatogram of B. radicata spore and sporophore powder

The test results were submitted to the National Institute of Standards and Technology (NIST) library, we analyzed the mass chromatograms of SPAF-1, the results were showed in Table 2. Peak1 revealed a peak of $\mathrm{m} / \mathrm{z} 116(\mathrm{M}+\mathrm{H})$, by comparing in NIST, the substance were 2-propyl-1-pentanol. Peak2 revealed peaks of $\mathrm{m} / \mathrm{z} 158,145,130,141(\mathrm{M}+\mathrm{H})$, by comparing in NIST, the substances may include decanal, $n$-decanol and $2 \mathrm{E}$-decanol, The results are showed in Table 2.

Table 2

chemical composition and antifungal activity of alcohol extract from B. radicata

\begin{tabular}{|c|c|c|c|c|c|c|}
\hline \multirow[t]{2}{*}{ name } & time & MIC & \multirow[t]{2}{*}{ content(\%) } & \multirow[t]{2}{*}{ chemical name } & molecular & molecular \\
\hline & $(\min )$ & $(\mu \mathrm{g} / \mathrm{ml})$ & & & formula & weight \\
\hline peak1 & 8.791 & 250 & 13.6 & 2-propyl-1-pentanol & $\mathrm{C}_{7} \mathrm{H}_{16}$ & 116 \\
\hline \multirow[t]{3}{*}{ peak2 } & 17.83 & 62.5 & 24.3 & decanal & $\mathrm{C}_{10} \mathrm{H}_{19} \mathrm{O}$ & 156 \\
\hline & & 31.2 & 27.9 & n-decanol & $\mathrm{C}_{10} \mathrm{H}_{21} \mathrm{O}$ & 158 \\
\hline & & 31.2 & 21.2 & 2E-decanol & $\mathrm{C}_{10} \mathrm{H}_{21} \mathrm{O}$ & 158 \\
\hline
\end{tabular}

Among them, decanol, n-decanol and 2E-decanol can inhibite the growth of T. rubrum at minimum inhibitory concentration of $62.5,31.2$ and $31.2 \mu \mathrm{g} / \mathrm{ml}$.

\section{FT-IR analysis of SPAF-1}

The FT-IR spectral results of alcohol extract, SPAF-1 and EF are shown in Fig. 4, the differences range among them are from $1100 \mathrm{~cm}^{-1}$ to $1800 \mathrm{~cm}^{-1}$ and $720 \mathrm{~cm}^{-1}$ to $900 \mathrm{~cm}^{-1}$. The broad stretch of frequency from $3500-3200 \mathrm{~cm}^{-1}$ was assigned to the hydroxyl group. There are no stretching vibrations at $1600,1580,1500$ and $1450 \mathrm{~cm}^{-1}$ which is considered to no aromatics in alcohol extract, EF and SPAF-1. In addition, the band obtained at $1433 \mathrm{~cm}^{-1}$ (SPAF-1) and $1652 \mathrm{~cm}^{-1}$ (alcohol) is assigned to the stretching vibrations of unsaturated $-C=O$ and the stretch from $1300 \mathrm{~cm}^{-1}$ to $1000 \mathrm{~cm}^{-1}$ was attributed to $-\mathrm{C}-\mathrm{O}$. The $-\mathrm{C}=\mathrm{O}$ and $-\mathrm{C}-\mathrm{O}$ stretching vibrations could be due to aldehyde group and hydroxyl group. The absorbance signals at 2930, 2932, and from 2300 to $2500 \mathrm{~cm}^{-1}$ could be explained by a long fat chain existing in the compounds. Decanal, n-decanol, 2E-decanol and 2Propyl-1-pentanol as components of SPAF-1 were verified by FT-IR.

Figure 4. FT-IR spectral of SPAF-1, alcohol extract and EF from HFUT-PB1 
To investigate the changes in shape and ultrastructure of T.rubrum cells, cells were examined after cocultivation with SPAF-1 by transmission electron microcopy. As shown in Fig. 5A. The membrane of the non-inoculated control cells was intact with uniformly distributed cytoplasm and electron density inside the cells. In contrast, more than $30 \%$ of $T$. rubrum cells showed concentrated cytoplasm and altered cell morphology after co-cultivation with SPAF-1 (Fig. 5B).As indicated by the red arrow 1, the cell membrane is badly shrunk out of wall. As indicated by the red arrow 2 , the cell wall is obviously thinner and the edge is blurred comparing with the control. which may increase membrane permeability and cause leakage of intracellular substances.

Figure 5. Transmission electron microscope images of T. rubrum co-cultured with SPAF-1

\section{Conclusions}

In this paper, we successfully separate SPAF from alcohol extract of $B$. radicata. The antifungal effect of SPAF is similar to positive control. The compound SPAF was characterized as decanal(24.3\%) ndecanol(27.9\%), 2E-decenol (21.2\%) and 2-Propyl-1-pentanol (13.6\%) by GC-MS, FT-IR and HPLC analysis. They could inhibite the growth of $T$. rubrum at minimum inhibitory concentration of $62.5 \mu \mathrm{g} / \mathrm{ml}$, $31.2 \mu \mathrm{g} / \mathrm{ml}, 31.2 \mu \mathrm{g} / \mathrm{ml}$ and $250 \mu \mathrm{g} / \mathrm{ml}$ respectively. TEM (transmission electron microscope) analysis showed altered surface morphology in the majority of T. rubrum cells after treatment with SPAF.

\section{Methods}

\section{Tested sample and pathogenic microbiology}

Tested puffball was isolated from pine forest of Jiangxi province, China and identified as Bovistella radicata (Mont.) Pat. The other tested puffballs included Calvatia gigantea, Calvatia lilacina Lloyd, Lasiosphaera fenzlii, and Lycoperdon pyriforme purchased from Anhui Bozhou traditional Chinese medicine commodity trading center. All of these puffball specimens were dried and deposited at herbarium of Department of Biology, Hefei University of Technology.

The four tested pathogenic bacterias included Staphylococcus aureus (ATCC 6538), Bacillus subtilis (ATCC 6051), Escherichia coli (ATCC 8739) and Pseudomonas aeruginosa (ATCC 15442), four fungi Trichophyton rubrum(ATCC 28188), Trichophyton mentagrophytes(ATCC 9533), Epidermophyton floccosum(ATCC 52066), and Candida albicans (ATCC 10231).

\section{In Vitro Antagonistic Activity of Puffball}

The examined methods were the minimum inhibitory concentrations (MICs)(Negi et al.2003)and zone of inhibitions (ZOIs). MIC value was determined in the 96 -well plates by the double micro dilution $\operatorname{method}(7.8 \sim 250 \mu \mathrm{g} / \mathrm{mL})$ against pathogens. ZOI $(100 \mu \mathrm{g} / \mathrm{ml})$ was also evaluated ${ }^{[33]}$, Terbinafine and Gentamicin sulfate as the positive control. 


\section{Alcohol extraction by Soxhlet system}

Puffball samples include spore and sporophore powder. The Soxhlet system includes extraction bottle, extraction tube and condenser. When extracting, the samples were wrapped in a degreased filter paper bag and put into the extraction tube. Alcohol was added into the extraction bottle, the extraction bottle was heated, alcohol was gasified, risen, condensed, dripped into the extraction tube, the bioactive components were extracted into the extraction bottle. so that the cycle reciprocates untile the extraction is complete.

\section{The chemical constituents of alcohol extraction by GC-MS}

The alcohol extracts were recorded on a GC-MS(Gas Chromatography-Mass Spectrometer) system. One microliter of alcohol extract of spore and sporophore powder was injected into a DB-5MS capillary column coated with $5 \%$ diphenyl cross-linked 95\% dimethylpolysiloxane (30 m $\times 250 \mu \mathrm{m}$ inner diameter, $0.25 \mu \mathrm{m}$ film thickness; J\&W Scientific, Folsom, CA, USA). The alcohol extract were injected in the splitless mode. Helium was used as the carrier gas. The front inlet purge flow was $1 \mathrm{~mL} / \mathrm{min}$, and the gas flow rate through the column was $20 \mathrm{~mL} / \mathrm{min}$. The initial temperature was kept at $40{ }^{\circ} \mathrm{C}$, held for $3.0 \mathrm{~min}$, then raised to $150{ }^{\circ} \mathrm{C}$ at a rate of $10{ }^{\circ} \mathrm{C} / \mathrm{min}$. The temperature was kept for $10 \mathrm{~min}$ at $150{ }^{\circ} \mathrm{C}$. The mass spectrometer was operated in electronionization (EI) mode at $70 \mathrm{eV}$. The injection, transfer line, and ion source temperatures were 150,250 , and $230{ }^{\circ} \mathrm{C}$, respectively. The mass spectrometry data were acquired in full-scan mode with an $\mathrm{m} / \mathrm{z}$ range of $10-500 \mathrm{u}$ at a rate of $20 \mathrm{u}$ spectra per second after a solvent delay of $210 \mathrm{~s}$. Peaks were identified by comparing with the mass spectra data from the National Institute of Standards and Technology (NIST) spectral library.

\section{HPLC analysis of alcohol extract and SPAF-1 from Bovistella radicata (Mont.) Pat}

Alcohol extract from B. radicata was also analyzed via high-performance liquid chromatography (HPLC) coupled with an ultraviolet (UV) detector (Agilent, 1260 Infinity II Prime, USA). The aim was to identify the most active compounds in the fractions of the puffballs. A C18 reversed-phase column (Hypersil Gold 25 $\mathrm{mm} \times 2.1 \mathrm{~mm}, 1.8 \mu \mathrm{m}$, Thermo Scientific, Massachusetts, USA) was used with the following solvent system: $A=$ acetonitrile, $B=0.15 \%$ ammonium acetate- water. The gradient elution was $7 \% A$ in 5 min, $7-$ $10 \% \mathrm{~A}$ in $3 \mathrm{~min}, 10 \% \mathrm{~A}$ in $2 \mathrm{~min}, 10-15 \% \mathrm{~A}$ in $5 \mathrm{~min}, 15 \% \mathrm{~A}$ in $3 \mathrm{~min}, 5-15 \% \mathrm{~A}$ in $2 \mathrm{~min}$. The LC system was operated at a flow rate of $1.0 \mathrm{~mL} / \mathrm{min}$ for $20 \mathrm{~min}$. The injection volume was $5 \mu \mathrm{L}$, and the detection was at $220 \mathrm{~nm}$.

\section{FT-IR analysis of SPAF-1}

The FT-IR(Fourier transform infrared spectroscopy) spectra of samples were recorded using a NICOLET 5700 Fourier Transform Infrared Spectrometer (provided by Nicolet Instrument Co., U.S.A) using potassium bromide $(\mathrm{KBr})$ pellets. The pellets were designed by blending the sample and $\mathrm{KBr}$ at a ratio of 1:100 and were ground into particles smaller than $0.1 \mathrm{~mm}$. The FT-IR measurement scanned the range from 400 to $4000 \mathrm{~cm}^{-1}$. A He-Ne laser source operating at $0.5 \mathrm{~W}$ was utilized for sample excitation. 


\section{Transmission Electron Microscopy}

Overnight cultures of $T$. rubrum. were on PDA. The wells $(5.0 \mathrm{~mm}$ in diameter) were cut from PDA medium, The tested compounds (SPAF-1) were added to the wells, the wells added normal saline were used as controls, then incubated at $28^{\circ} \mathrm{C}$ for 48 hours. Following the incubation period samples were pick up from PDA and fixed overnight in $2.5 \%$ glutaraldehydein PBS (phosphate-buffered saline), washed three times in PBS and postfixed overnight in $1 \%$ osmium tetroxide. Following ethanol dehydration, probes were embedded in Epon resin (Sigma-Aldrich), cut on a ultramicrotome Leica UC7 and contrasted in uranyl acetate and lead citrate. Transmission electron microscopy studies were performed using a Philips CM100 electron microscope ${ }^{[34]}$.

\section{Discussion}

In the present study, $B$. radicata from Jiangxi province, China, shows remarkable antifungal activities. These data are consistent with previous findings on the minimum inhibitory concentrations (MICs) of $B$. radicata ${ }^{[19]}$.

According to the Chinese Pharmacopeia, the main anti-microorganism activity of the puffball is against $S$. aureus and P.aeruginosa. The antifungal function of puffballs has not been reported previously. The novel antimicrobial activities of $B$. radicata might be due to different geographic sources of the material used and different strains used ${ }^{[22]}$.

In vitro assays demonstrated that alcohol extract and SPAF- 1 from $B$. radicata were able to suppress the mycelial growth of T. rubrum and T. mentagrophytes. The MICs of SPAF-1 from alcohol extract are $31.2 \mu \mathrm{g} / \mathrm{ml}$ and $31.2 \mu \mathrm{g} / \mathrm{ml}$ against $T$. rubrum and T. mentagrophytes, respectively. Terbinafine was used as a positive control in this study with MIC values 62.5 and $31.2 \mu \mathrm{g} / \mathrm{ml}$. The antifungal effect of SPAF-1 was similar with that of positive control.

The SPAF-1 were purified by macroporous resin D-101 and submitted to GC-MS analysis. The main constituents were identified alcohols(62.7\%) and aldehydes(30.2\%), the main alcohols were ndecanol(27.9\%), 2E-decenol(21.2\%) and 2-ethyl-1-Hexanol(13.6\%), while the major aldehydes were decanal(24.3\%). alcohols, aldehydes and 2-Propyl-1-pentanol have a long alphatic chain. Alphatic alcohols are the most widespread compounds found in plants, and are also known to cause a variety of biochemical responses ${ }^{[23]}$. Long-chain aliphatic alcohols ranging in chain length from 6 to greater than 20 carbon atoms can inhibit the growth of various types of bacteria and fungi ${ }^{[24-26]}$. n-decanol, $2 \mathrm{E}-$ decenol are volatile organic compounds (VOC) and have been reported to possess various bioactivities ${ }^{[27]}$. Previous studies reported that 1-Decanol exhibited antibacterial ${ }^{[28]}$ and antimicrobial ${ }^{[29]}$ activities. Begnami et al (2010) found that 1-decanol, 2E-decenol, 2Z-dodecenol, and aldehydes from Coriandrum sativum L(Apiaceae) exhibited effective growth-inhibitory activities against five species of Candida albicans ${ }^{[30]}$, while activities against $T$. rubrum and T. mentagrophytes, the main pathogens of tinea pedis have not been reported. 
All these aliphatic alcohols and aldehydes obtained from B. radicata alcohol extracts increase the fluidity of the membrane and are known to inhibit the key enzyme of saturated fatty acids ${ }^{[31]}$. The aliphatic alcohols also have one hydroxyl group. The hydroxyl group mainly determines the hydrophilicity of the molecule, resulting in much easier interaction with its target in a living organism [32].

Future work concentrating on determining the antifungal mechanisms of aliphatic alcohols and aldehydes will be performed, which will be helpful in laying a foundation for overcoming the drug resistance that pathogens quickly develop against antibiotic drugs.

\section{Abbreviations}

AMB

Amphotericin B

PDA

Potato Dextrose Agar

El

electronionization

HPLC

High Performance Liquid Chromatography

UV

ultraviolet

MIC

Minimum Inhibitory Concentration

NIST

National Institute of Standards and Technology

GC-MS

Gas Chromatography-Mass Spectrometer

FT-IR

Fourier-Transform Infrared

VOC

Volatile Organic Compound

\section{Declarations}

Ethics approval and consent to participate

Not applicable

Consent for publication

Not applicable 
Availability of data and material

Not applicable

Competing interests

Not applicable

Funding

This study was supported by the National Natural Science Foundation of China (Grant No. 31371844; 31071556) and the Science and Technology Department of Anhui province, PR of China (Grant No. 130103215)

Authors' contributions

Yong ye conceived and designed the experiments. Yong ye performed the experiments and analyzed the data. Qinghua zeng analyzed the data. Yong ye wrote and edited the manuscript. The excellent technical support by Chuanxun Yuan and Qingmei Zeng

Acknowledgements

Not applicable

\section{References}

1. References.

2. Alteras I, Cafri B, Feuerman EJ. The high incidence of Tinea pedis and unguium in patients with Kaposi's sarcoma. Mycopathologia. 1981;74(3):177-9.

3. Koltin Y, Hitchcock CA. The search for new triazole antifungal agents. Curr Opin Chem Biol. 1997;1(2):176-82.

4. Erbagci Z, Tuncel A, Zer Y, Balci I. A prospective epidemiologic survey on the prevalence of onychomycosis and dermatophytosis in male boarding school residents. Mycopathologia. 2005;159(3):347-52.

5. Miyajima Y, Satoh K, Uchida T, Yamada T, Abe M. Rapid real-time diagnostic PCR for Trichophyton rubrum and Trichophyton mentagrophytes in patients with tinea unguium and tinea pedis using specific fluorescent probes. J Dermatol Sci. 2013;69(3):229-35.

6. Daneshmend DTK, Warnock DW. Clinical Pharmacokinetics of Systemic Antifungal Drugs. Clin Pharmacokinet. 1983;8(1):17-42.

7. Patel VM, Schwartz RA, Lambert WC. Topical Antiviral and Antifungal Medications in Pregnancy: A Review of Safety Profiles. J Eur Acad Dermatol Venereol, 2017;31(9). 
8. Francis P, Walsh TJ. Evolving Role of Flucytosine in Immunocompromised Patients: New Insights into Safety, Pharmacokinetics, and Antifungal Therapy. Clin Infect Dis. 1992;15(6):1003-18.

9. Stamm AM, Diasio RB, Dismukes WE, Shadomy SM, Cloud GA. Toxicity of amphotericin B plus flucytosine in 194 patients with cryptococcal meningitis. Am J Med. 1987;83(2):236-42.

10. Vermes A, Guchelaar HJ, Dankert J. Flucytosine: a review of its pharmacology, clinical indications, pharmacokinetics, toxicity and drug interactions. J Antimicrob Chemother. 2000;46(2):171-9.

11. Denning DW, Venkateswarlu K, Oakley KL, Anderson MJ. NJ Manning. Itraconazole resistance in Aspergillus fumigatus. Antimicrob Agents Chemother. 1997;41(6):1364-8.

12. Subissi A, Monti D, Togni G, Mailland F. Ciclopirox: recent nonclinical and clinical data relevant to its use as a topical antimycotic agent. Drugs. 2010;70(16):2133-52.

13. Lushchak VI. Contaminant-induced oxidative stress in fish: a mechanistic approach. Fish Physiology Biochemistry. 2016;42(2):711-47.

14. Rajendra U, Campbell LT, Donlin MJ, Aurora R, Lodge JK. Global Transcriptome Profile of Cryptococcus neoformans during Exposure to Hydrogen Peroxide Induced Oxidative Stress. Plos One. 2013;8(1):e55110.

15. Ribeiro WLC, Macedo ITF, Rondon FCM, Bevilaqua CML. Essential Oils and Their Bioactive Compounds in the Control of Gastrointestinal Nematodes of Small Ruminant. Acta Scientiae Veterinari. 2018;46(1522):1-14.

16. Bates ST, Roberson RW, Desjardin DE. Arizona gasteroid fungi I: Lycoperdaceae (Agaricales, Basidiomycota). Fungal Divers. 2009;37(37):153-207.

17. LIANG Y. Hemostatic material for use in variety of fresh tissue trauma, comprises microporous starch, hyaluronic acid, collagen and puffball spores at specific weight percentage: $2016 ; C N$, CN105664233-A.

18. Jiang K. Beverage useful for relieving cough, moisturizing lungs and improving immunity, contains Asparagus, coltsfoot, Sonchus arvensis, maidenhair, lotus seed, corni fructus, puffball, galangal, boneset, club moss herb, sugar and preservative:2017; CN,CN106729277-A.

19. Lam YW, Ng TB, Wang HX. Antiproliferative and Antimitogenic Activities in a Peptide from Puffball Mushroom Calvatia caelata. Biochemical Biophysical Research Communications. 2001;289(3):7449.

20. Ye Y, Liu K, Zeng QH, Zeng QM. Antimicrobial activity of puffball(Bovistella radicata) and separation of bioactive compounds. Amb Express. 2017;7(1):99.

21. Petrović $P$, Vunduk J, Klaus A, Kozarski M, Nikšić M. Biological potential of puffballs: A comparative analysis. Journal of Functional Foods. 2016;21:36-49.

22. Negi PS, Anandharamakrishnan C, Jayaprakasha GK. Antibacterial activity of Aristolochia bracteata root extracts. J Med Food. 2003;6(4):401-3.

23. Ali NAA, Mothana RAA, Lesnau A, Pilgrim H, Lindequist U. Antiviral activity of Inonotus hispidus. Fitoterapia. 2003;74(5):483-5. 
24. Peira E, Carlotti ME, Trotta C, Cavalli R, Trotta M. Positively charged microemulsions for topical application. Int J Pharm. 2008;346:119-23.

25. Fujita KI, Fujita T, Kubo I. Antifungal activity of alkanols against Zygo saccharomyces bailii and their effects on fungal plasma membrane. Phytother Res. 2008;22:1349-55.

26. Kubo I, Muroi $H$, Kubo A. Structural functions of antimicrobial long-chain alcohols and phenols. Bioorg Med Chem. 1995;3:873-80.

27. Suprapta DN, Arai K, Iwai H. Effects of volatile compounds on arthrospore germination and mycelial growth of Geotrichum candidum, citrus race. Mycoscience. 1997;38:31-5.

28. Jing Chen W, Wang C, Shi J, Wan, Li Deng. Determination of Four Volatile Compounds with AntiInflammatory Biological Activity in Thunb. by Gas Chromatography and Gas Chromatography-Mass Spectrometry. Anal Lett. 2014;47:730-41.

29. Togashi N, Shiraishi A, Nishizaka M, Matsuoka K, Endo K, Hamashima H. Inoue Y.Antibacterial activity of long-chain fatty alcohols against Staphylococcus aureus. Molecules. 2007;12:139.

30. Ding CH, Du XW, Xu Y, Xu XM, Mou JC. Screening for Differentially Expressed Genes in Endophytic Fungus Strain 39 During Co-culture with Herbal Extract of its Host Dioscorea nipponica, Makino. Curr Microbiol. 2014;69(4):517-24.

31. Begnami AF, Duarte MC, Furletti T, Rehder V. V L G. Antimicrobial potential of Coriandrum sativum L. against different Candida species in vitro. Food Chem. 2010;118:74-7.

32. Maguireboyle SJ, Barron AR. Organic compounds in produced waters from shale gas wells. Environmental Science Processes Impacts. 2014;16:2237.

33. Calzada F, AlanãS AD. Additional antiprotozoal flavonol glycosides of the aerial parts of Helianthemum glomeratum. Phytother Res. 2007;21(1):78-80.

34. Geetha R, Sathian CT, Prasad V, Gleeja VL. Efficacy of purified antimicrobial peptides from lactic acid bacteria against bovine mastitis pathogen. Asian J Dairy Food Res. 2015;34:259-64.

35. Aghayeva DN, Lutz M, Piatek M. Transmission electron microscopy of Tuberculina species (Helicobasidiales) reveals an unique mode of conidiogenesis within Basidiomycota. Fungal Biology. 2016;120(8):1010-6.

36. 238125-47625Figure1. zone of inhibition(ZOI) of spore and sporophore powder from B.radicata

37. is ZOI of. alcohol extract from $B$. radicata spore powder; 1 is alcohol extract from $B$. radicata sporophore powder; and 2 is alcohol extract from L.fenzlii Reich. "+" is positive control and "-" is negative control.

38. -190500-304800Figure. 2. HPLC chromatograms of SPAF-1 and alcohol extract from B. radicata spore powder.

39. A.; HPLC chromatograms of alcohol extract from B. radicata spore powder.

40. B. HPLC chromatograms of SPAF-1.

\section{Figures}




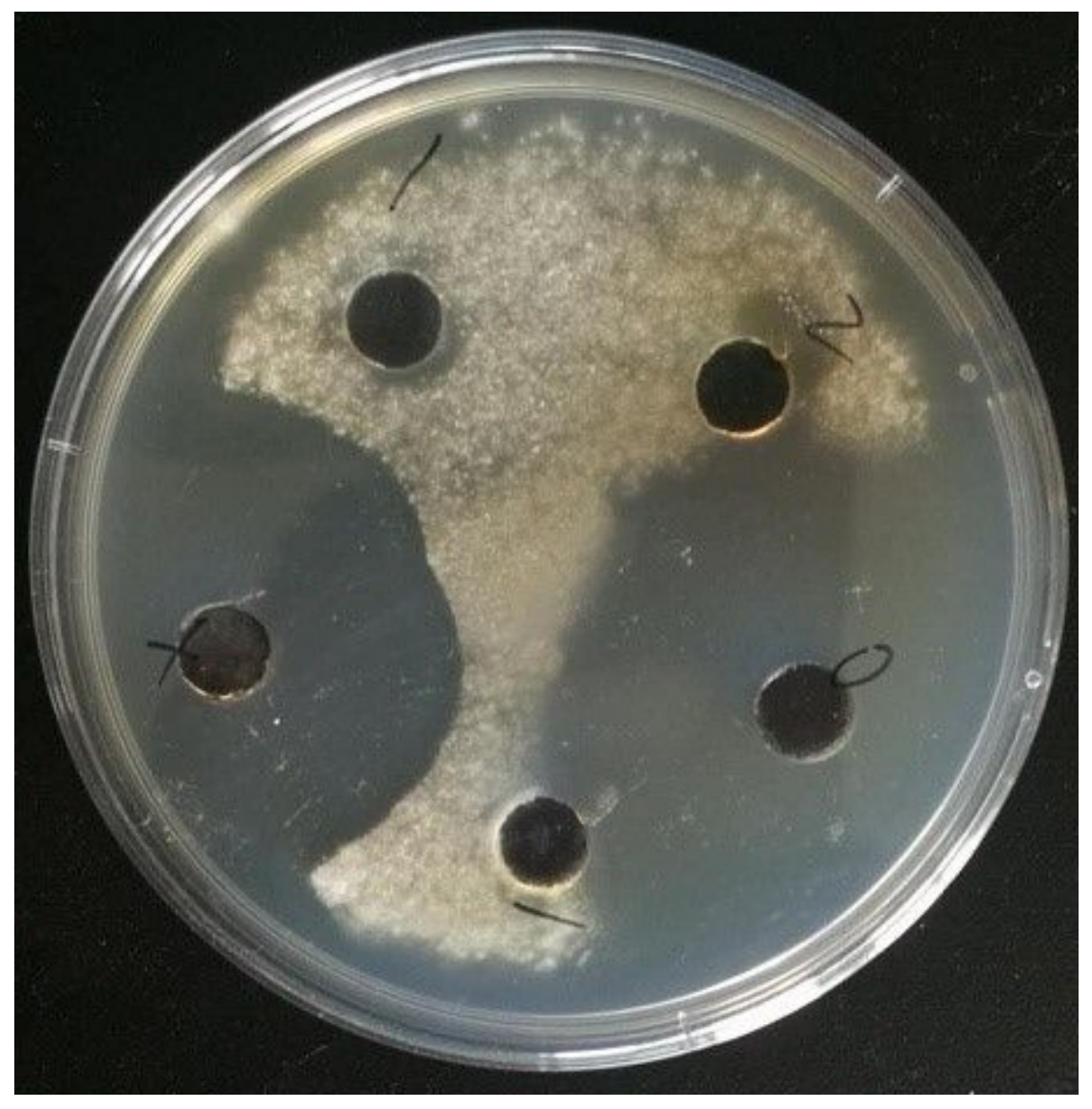

\section{Figure 1}

zone of inhibition(ZOI) of spore and sporophore powder from B.radicata 0 is $\mathrm{ZOI}$ of alcohol extract from $B$. radicata spore powder; 1 is alcohol extract from B. radicata sporophore powder; and 2 is alcohol extract from L.fenzlii Reich. " + " is positive control and "-" is negative control. 


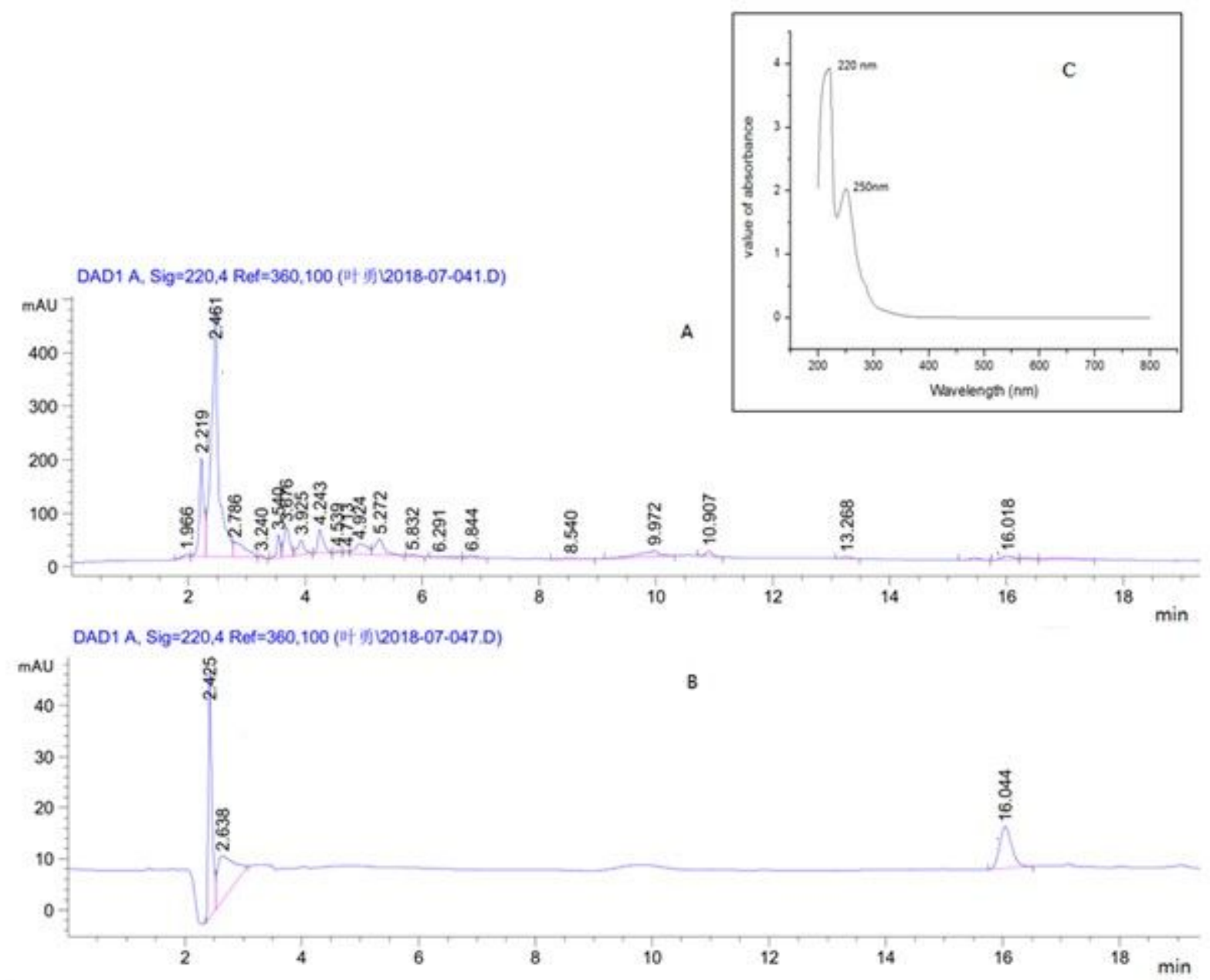

Figure 2

HPLC chromatograms of SPAF-1 and alcohol extract from B. radicata spore powder A :; HPLC chromatograms of alcohol extract from B. radicata spore powder B: HPLC chromatograms of SPAF-1 


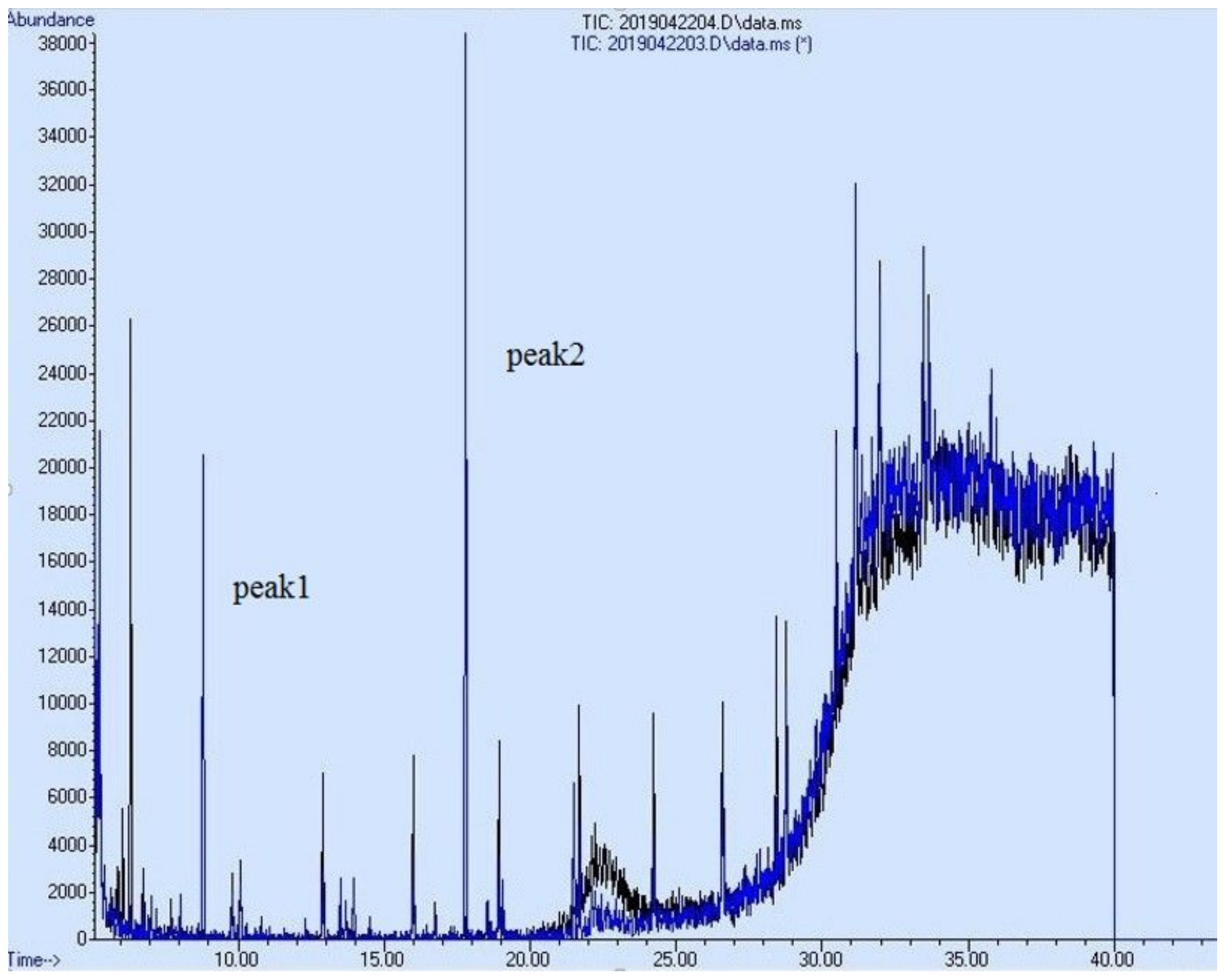

Figure 3

Fitting gas chromatogram of B. radicata spore and sporophore powder 


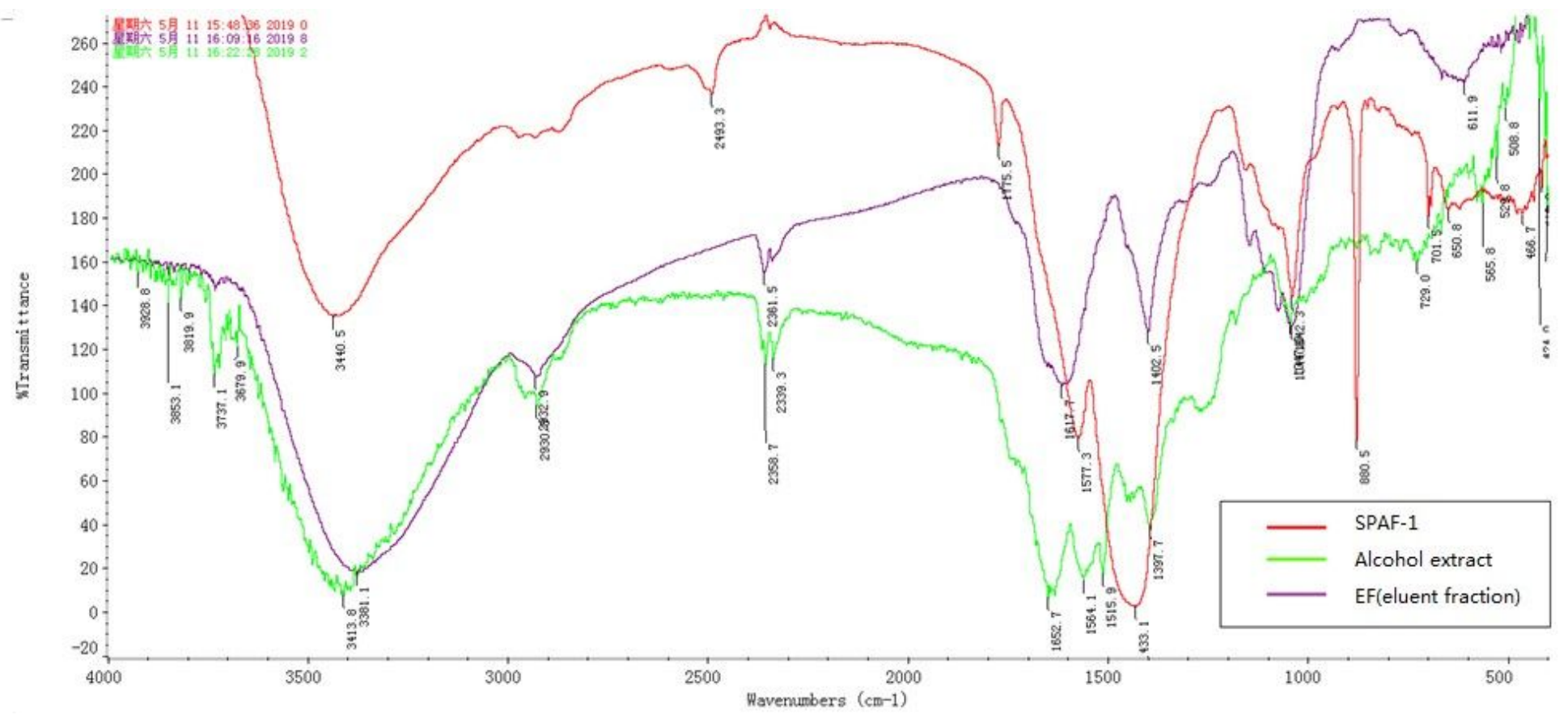

Figure 4

FT-IR spectral of SPAF-1, alcohol extract and EF from HFUT-PB1

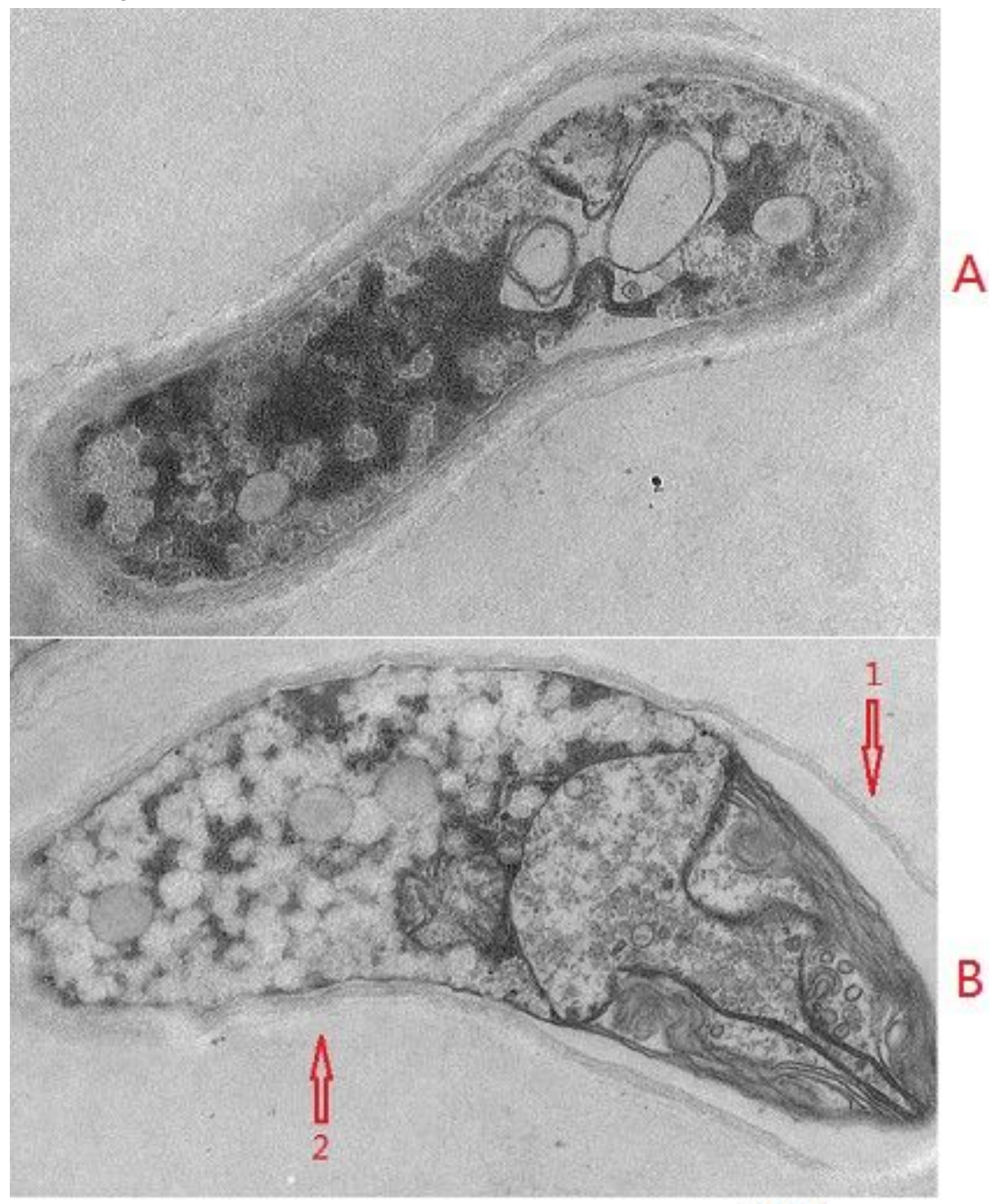

H1um

Page $16 / 17$ 
Figure 5

Transmission electron microscope images of T. rubrum co-cultured with SPAF-1. (A) Untreated control T. rubrum. (B) T. rubrum co-cultured with SPAF-1 